\title{
Effect of Silica Fume and Slag on Compressive Strength and Abrasion Resistance of HVFA Concrete
}

\author{
Alaa M. Rashad*, Hosam El-Din H. Seleem, and Amr F. Shaheen
}

(Received March 6, 2013, Accepted August 8, 2013)

\begin{abstract}
In this study, portland cement (PC) has been partially replaced with a Class F fly ash (FA) at level of $70 \%$ to produce high-volume FA (HVFA) concrete (F70). F70 was modified by replacing FA at levels of 10 and $20 \%$ with silica fume (SF) and ground granulated blast-furnace slag (GGBS) and their equally combinations. All HVFA concrete types were compared to PC concrete. After curing for 7, 28, 90 and 180 days the specimens were tested in compression and abrasion. The various decomposition phases formed were identified using X-ray diffraction. The morphology of the formed hydrates was studied using scanning electron microscopy. The results indicated higher abrasion resistance of HVFA concrete blended with either SF or equally combinations of SF and GGBS, whilst lower abrasion resistance was noted in HVFA blended with GGBS.
\end{abstract}

Keywords: compressive strength, abrasion, recycle, cementitious materials, HVFA.

\section{Introduction}

The use of high-volume fly ash (HVFA) concrete is one of the solutions to eliminate the environmental degradations being caused by cement industry. The cement industry, itself, is responsible for about 5-8\% of world's carbon dioxide emissions (Rashad and Zeedan 2011), emits $\mathrm{SO}_{2}$ and $\mathrm{NO}_{x}$ which can cause the greenhouse effect and acid rain (Rashad and Zeedan 2011; Park and Kang 2008), responsible for global warming, and consumes a lot of natural resources and energy (Rashad and Zeedan 2011; Taylor 1997; Rashad et al. 2013).

HVFA is an approach to maximize the FA input in concrete. However, HVFA concrete has been not a unified definition yet now. Sivasundaram et al. (1990) believed that the replacing cement ratio above $30 \%$ with FA in concrete is defined as HVFA concrete. But $40 \%$ is defined as upper limit in many state standards or regulations, the quantity of FA in concrete do not exceed $40 \%$ stipulated in many cases. Therefore Dunstan et al. (1992) believed that above $40 \%$ FA in concrete defined as HVFA concrete is suitable. Some authors suggested that the concrete may be defined as HVFA concrete when the quantity of FA exceeds of cement in cementitious material (i.e. the quantity of FA is more than $50 \%$ ). Bilodeau and Malhotra (1992a) suggested that the quantity of FA in HVFA concrete must be 50-70\%, namely the volume of FA is larger than cement in concrete. LEED

Housing and Building National Research Center, Cairo, Egypt.

*Corresponding Author; E-mail: alaarashad@yahoo.com Copyright ( $\odot$ The Author(s) 2013. This article is published with open access at Springerlink.com
(PCA 2005) pointed that HVFA concrete included up to $40 \%$ of FA in cement.

Silica fume (SF) composed of submicron particles of silicon dioxide, is produced by electric arc furnace as a byproduct waste of the production of metallic silicon or ferrosilicon alloys. Their production amounts worldwide, especially in industrial countries, have reached alarming proportions. It is estimated that current global output of SF is, at most, between 1 and 1.5 million tonnes per year (Sakulich 2011; Rashad and Khalil 2013). Today the utilization of SF in composite technology has increased recently (Mei and Chung 2002). The first utilization of SF in concrete was reported in 1952 by a Norwegian researcher. It was only in the late 1970s that SF started to be as a supplementary cementitious material in concrete in Scandinavia. It was not until the 1980s that it began to be used in this way in North America (Koksal et al. 2008).

Ground granulated blast-furnace slag (GGBS) is a byproduct obtained in the manufacturing of iron in a blast furnace where iron ore, limestone and coke are heated between 1,400 and 1,600 ${ }^{\circ} \mathrm{C}$. Quenching process of molten slag by water is converting it into a fine (no larger than $5 \mathrm{~mm}$ diameter), granulated slag of whitish color. The rapid cooling prevents the formation of larger crystals. The resulting granular material comprises some 85-95\% noncrystalline calcium-aluminosilicates (glassy materials) that higher in energy than the crystalline material (Swamy 1986). Although there are many uses of GGBS in concretes, the vast majority of GGBS is still disposed of in landfills.

The abrasion resistance of floor constructions from concrete with cement binders is very important for their service life, especially in industrial enterprises. Deterioration of concrete surfaces is caused by forms of wear due to various exposures, such as erosion, cavitation, and abrasion. 
Abrasion wear occurs due to rubbing, scraping, skidding or sliding of objects on concrete surface. This form of wear is observed in pavements, floors or other surfaces on which friction forces are applied due to relative motion between the surfaces and moving objects.

The principal factors affecting the abrasion resistance of concrete can be the environmental conditions, aggregate type, dosage of aggregate, the concrete strength, the mixture proportioning, the use of special cement, the use of supplementary cementitious materials, water/binder $(w / b)$ ratio and the addition of fiber. Two other important factors have an effect on abrasion resistance: surface finishing and curing conditions. Numerous studies on the abrasion resistance of concrete have been carried out to show that the abrasion resistance of concrete is strongly influenced by compressive strength, surface finishing techniques, curing types, aggregate properties and testing conditions (Atiş 2002). There are two views on the relationship between compressive strength and abrasion resistance of concrete specimens. The first is that compressive strength is the most important factor governing the abrasion resistance of concrete (Naik et al. 1995) and the abrasion resistance of concrete follows its compressive strength (Atiş 2002, 2003a; Mehta 1986; Li et al. 2006; Rashad 2013). For instance, some authors (Rashad 2013; Naik et al. 1994, 2002; Yen et al. 2007) indicated that the relationship between compressive strength and abrasion resistance of concrete is linear, whilst Atiş (2002) pointed out that this relation is hyperbolic. The second view is that the abrasion resistance of concrete is independent only on its compressive strength (Langan et al. 1990; Nanni 1989) where a number of investigation have shown that curing practice types (Nazari and Riahi 2011; Riahi and Nazari 2011) and surface finishing techniques have a strong influence on the abrasion resistance of concrete (Ytterburg 1971; Nanni 1988).

Liu (1981) compared the abrasion resistance of portland cement (PC) concrete and FA concrete having $25 \%$ cement replacement. Abrasion resistance of concrete with or without FA was similar up to $36 \mathrm{~h}$ of abrasion testing. Beyond $72 \mathrm{~h}$ testing, the FA concrete lost about $25 \%$ more weight than the PC concrete. Gelber and Klieger (1986) studied the abrasion resistance of concrete containing ten different sources of Class F and Class C FA. Concrete mixtures were proportioned to have $25 \% \mathrm{FA}$, by weight of total cementitious materials. They reported that the abrasion resistance of Class C FA concretes was generally superior to Class F FA concretes. Tikalsky et al. (1988) determined the abrasion resistance of concrete having cement replacement in the range of $0-35 \%$ with Class $\mathrm{F}$ and Class $\mathrm{C}$ FA. Concretes containing Class $\mathrm{C}$ FA performed better than that for plain PC concretes and concretes containing Class F FA.

Ukita et al. (1989) evaluated the abrasion resistance of concrete incorporating a low-calcium FA in the range of $0-35 \%$ of cement by volume. Test results indicated that at a $15 \%$ cement replacement with FA, abrasion resistance increased with fineness of FA. At $30 \%$ FA content, the abrasion resistance of concrete was lower than that for concrete without FA. Yen et al. (2007) investigated the abrasion resistance of HSC mixtures in which cement was partially replaced with Class F FA at levels of 15, 20, 25 and $30 \%$, by weight. They concluded that the abrasion resistances of FA concrete mixtures were improved by increasing compressive strength and decreasing $w / b$ ratio. The abrasion resistance of concrete with $15 \%$ FA was comparable to that of control without FA. Beyond $15 \%$ cement replacement, FA concrete showed lower resistance to abrasion compared to control concrete without FA. On the other hand Naik et al. (1995) partially replaced cement with Class C FA at levels of $15,30,40,50$ and $70 \%$. They reported that the abrasion resistance of concrete having cement replacement up to $30 \%$ was comparable to the reference concrete without FA. Beyond $30 \%$ cement replacement, FA concrete exhibited slightly lower resistance to abrasion relative to concrete without FA.

Barrow et al. (1989) investigated the abrasion resistance of concrete containing both ASTM Class F and Class C FA. The two types of FA were used to replace cement, by volume, by 25 or $50 \%$. Curing condition for tested specimens included combinations of $10,23.8$ and $37.7^{\circ} \mathrm{C}$ with 50 and $100 \% \mathrm{RH}$. They indicated that due to lack of proper curing, the abrasion resistance of FA concretes was less than those for concrete without FA. Naik and Singh (1991) investigated the effects of temperature and a Class F FA addition on concrete strength and abrasion resistance under simulated hot weather conditions. The results revealed that at $23{ }^{\circ} \mathrm{C}$, the abrasion resistance increased with increasing FA content, whilst at higher temperatures $\left(35-49{ }^{\circ} \mathrm{C}\right)$, the abrasion resistance was adversely affected by the inclusion of lowcalcium FA.

Langan et al. (1990) studied the compressive strength and the durability of concrete containing substitute materials at a $50 \%$ replacement level, by weight of cement. Seven FA, together with limestone as an inert filler material, were used as replacement materials. The results revealed that the presence of FA at high levels of cement replacement increased the weight loss due to abrasion at all ages relative to concrete without FA. Naik et al. (1992) determined the abrasion resistance of FA concretes. Both Class C (20-50\%) and Class F (40\%) mixtures were proportioned. A superplasticizer was added to the Class F FA concrete mixture to keep the $w / b$ ratio below 0.36 . Test results revealed that the Class C FA concrete mixtures (20-50\%) showed similar results, whilst the $40 \%$ Class F FA concrete mixture indicated a higher depth of wear relative to Class C FA mixtures. Bilodeau and Malhotra (1992b) studied the abrasion resistance of concrete incorporating high volumes of Class F FA. Superplasticized proportions were developed for concrete mixtures containing $55-60 \%$ FA of total cementitious materials. Their test results showed lower abrasion resistance of HVFA concretes relative to the concrete without FA. Carette et al. (1992) studied the abrasion resistance of airentrained, superplasticizer, high-volume Class F FA concrete. The content of FA ranged from 55 to $60 \%$ of the total cementitious materials. They indicated that some concrete exhibited significantly lower abrasion resistance than other concretes of similar or even lower compressive strength. On 
the other hand Naik et al. (1997) reported that strength and durability properties including abrasion resistance for the $40 \%$ FA mixture were either comparable or superior to the concrete without FA.

Bouzoubaâ et al. (2001) examined the abrasion resistance of concrete incorporating $58 \%$ Class F FA of total binding materials. Test results revealed that FA concrete had lower abrasion resistance than the concrete without FA. Atiş (2002) partially replaced cement with FA at levels of 50 and $70 \%$ in concrete mixtures prepared with various $w / b$ ratios. Superplasticizer was employed in some mixtures to control the concrete workability. They reported that for high strength grades $(>40 \mathrm{MPa})$, the abrasion resistance of HVFA concrete with $70 \%$ replacement of cement was higher than that of control concrete and concrete made with $50 \%$ FA. Naik et al. (2002) partially replaced cement with three different types of Class C FA at levels of 40, 50 and $60 \%$. The $w /$ $b$ ratio was kept constant at 0.3 for all mixtures. All concrete types were exposed to abrasion according to ASTM C 944. They reported that the $40 \%$ FA mixture was as abrasion resistant as the FA-free mixture. Beyond $50 \%$ FA content, abrasion resistance of FA concrete mixtures was slightly lower as compared with the reference mixture. Siddique (2010) studied the abrasion resistance of HVFA concrete in which cement was partially replaced with FA at levels of 40, 50 and $60 \%$, by weight. The results indicated that the abrasion resistance of concrete having cement replacement up to $40 \%$ was comparable to the normal concrete. Beyond $40 \%$ FA content, concretes exhibited slightly lower resistance to abrasion related to normal concrete. In another investigation Siddique (2004) studied the abrasion resistance of HVFA concrete where cement was partially replaced with FA at levels of 40,45 and $50 \%$, by weight. The results indicated that as FA content increased as the abrasion resistance decreased.

Kumar et al. (2007) partially replaced cement in concrete for pavements with FA at levels of 20, 30, 40, 50 and $60 \%$, by weight. They reported that the abrasion resistance decreased with the increase in FA content. The abrasion resistance of $60 \%$ FA at $w / b$ ratio of 0.3 was adequate to the pavement consideration. On the contrary Yaxic1 and Inan (2006) studied the abrasion resistance of different concrete mixtures having the same slump of $50 \pm 15 \mathrm{~mm}$. The mixtures included PC concrete, $30 \%$ SF replacement of cement, $25 \%$ FA replacement of cement, $5 \%$ FA replacement of sand, $10 \%$ FA replacement of sand and $15 \%$ FA replacement of sand, respectively. They reported that $25 \%$ FA, as a partial cement replacement, caused significant reduction in the abrasion resistance, whilst 5, 10 and $15 \%$ FA as sand replacement generally exhibited same abrasion resistance with $\mathrm{PC}$ concrete mixture.

Indeed, there is no published literature on compressive strength and abrasion resistance of HVFA concrete modified with SF, GGBS and their equally combinations. This paper presents the compressive strength and the abrasion resistance of HVFA concrete in which cement was partially replaced with FA at level of $70 \%$. Then, HVFA concrete modified with other cementitious materials, where
10 and $20 \%$ of FA was partially replaced with SF, GGBS and their equally combinations. This study also aims to respond extra four issues: lower emission of pollutants into atmosphere by replacing $\mathrm{PC}$, reduction in consumption of natural resources required in $\mathrm{PC}$ industry, reduction in the amount of fuel required in PC industry and eliminate FA, SF and GGBS disposals. However, this investigation will therefore add valuable knowledge to the HVFA system.

\section{Experiment}

\subsection{Materials}

\subsubsection{Cementitious Materials}

Commercially available PC, CEM I, $42.5 \mathrm{~N}$, of Blaine surface area $3,350 \mathrm{~cm}^{2} / \mathrm{g}$ and confirming to the Egyptian Standard specifications (ES 4756-1/2007) is used. The used FA in the current investigation obtained from disposal waste resulting from the combustion of pulverised coal in the coalfired furnaces. It is classified as low calcium Class F FA in ASTM-C618. Specific gravity of the FA was $2.4 \mathrm{t} / \mathrm{m}^{3}$. Its Blaine specific surface area was $4,000 \mathrm{~cm}^{2} / \mathrm{g}$. The GGBS was delivered from disposal waste resulting from steel industry of Helwan Steel Factory (Cairo, Egypt) in the form of water quenched fine grains. The GGBS was then finely ground in a laboratory ball mill, the fraction passing $100 \mu \mathrm{m}$ sieve was used through this investigation. The used SF in the current investigation obtained from disposal waste resulting from the ferro-silicon alloys industry. Its Blaine surface area and the specific gravity were $202,000 \mathrm{~cm}^{2} / \mathrm{g}$ and $2.32 \mathrm{t} / \mathrm{m}^{3}$, respectively. The relevant chemical compositions of all cementitious materials were evaluated by X-ray fluorescence (XRF) analysis and shown in Table 1. Figure 1 shows the diffractograms of raw FA, SF and GGBS samples analyzed by X-ray diffraction (XRD).

\subsubsection{Aggregates}

The used coarse aggregate is crushed dolomite stone (limestone) with nominal maximum size of $10 \mathrm{~mm}$. Locally available river sand confirming to the medium grading zone of the Egyptian Standard specification (ES 1109/2002) is employed.

\subsubsection{Chemical Admixture}

High-range water reducer (HRWR) has a sulphonated naphthalene base that is used at a dosage of $2.0 \%$ from the total cementitious materials weight (i.e. $81 / \mathrm{m}^{3}$ ) to accomplish high flowability.

\subsection{Mixtures Proportions}

A total number of eight mixtures were cast. All concretes were proportioned for an invariant effective $w / b$ ratio of 0.4 , of total cementitious materials, and total cementitious content of $400 \mathrm{~kg} / \mathrm{m}^{3}$. The first mixture (F0) was made of PC only as the binder, whilst the remaining mixtures were incorporated binary $(\mathrm{PC}+\mathrm{FA})$, ternary $(\mathrm{PC}+\mathrm{FA}+\mathrm{SF}, \quad \mathrm{PC}+\mathrm{FA}+\mathrm{GGBS})$ and quaternary 
Table 1 Oxide composition of cementitious materials after calculation from XRF results.

\begin{tabular}{|c|c|c|c|c|}
\hline Composition & $\mathrm{PC}$ & FA & $\mathrm{SF}$ & GGBS \\
\hline $\mathrm{CaO}$ & 63.47 & 4.76 & 0.98 & 45.88 \\
\hline $\mathrm{SiO}_{2}$ & 20.18 & 55.95 & 95.2 & 30.38 \\
\hline $\mathrm{Al}_{2} \mathrm{O}_{3}$ & 4.83 & 23.3 & - & 9.05 \\
\hline $\mathrm{MgO}$ & 2.47 & 1.85 & 0.431 & 5.39 \\
\hline $\mathrm{Fe}_{2} \mathrm{O}_{3}$ & 3.16 & 4.84 & 1.0 & 3.82 \\
\hline $\mathrm{SO}_{3}$ & 3.26 & 0.65 & 0.02 & 1.78 \\
\hline $\mathrm{K}_{2} \mathrm{O}$ & 0.52 & 1.82 & 1.03 & 0.31 \\
\hline $\mathrm{Na}_{2} \mathrm{O}$ & 0.16 & 0.91 & 0.91 & 0.52 \\
\hline $\mathrm{TiO}_{2}$ & 0.3 & 1.03 & - & - \\
\hline $\mathrm{MnO}$ & 0.22 & 0.05 & - & - \\
\hline $\mathrm{P}_{2} \mathrm{O}_{5}$ & 0.09 & 0.73 & - & - \\
\hline $\mathrm{CaCO}_{3}$ & - & - & - & - \\
\hline $\mathrm{Cl}^{-}$ & - & - & - & - \\
\hline L.O.I. & 2.18 & 3.47 & 0.429 & 1.41 \\
\hline
\end{tabular}

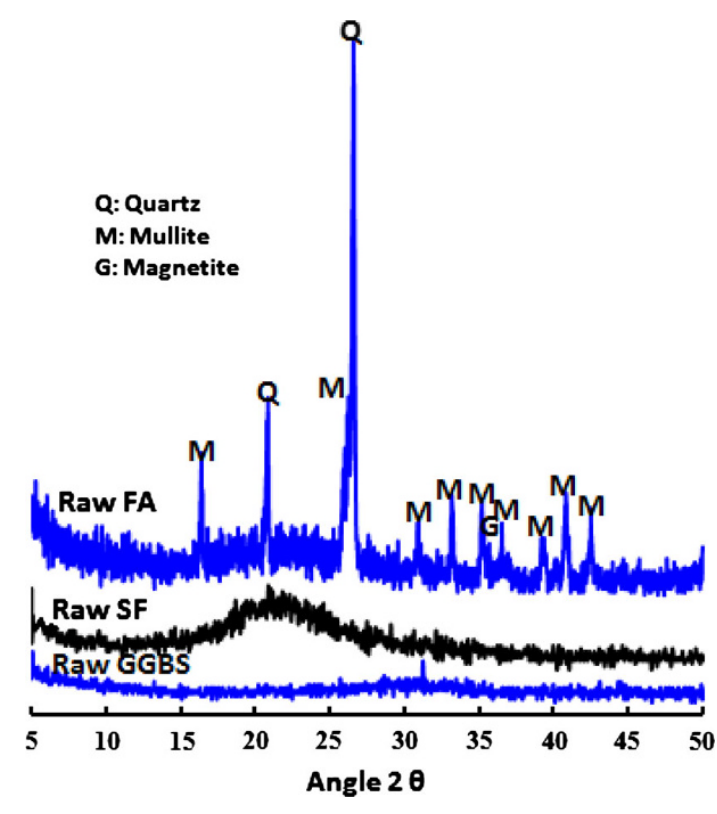

Fig. 1 XRD patterns for FA, SF and GGBS.

$(\mathrm{PC}+\mathrm{FA}+\mathrm{SF}+\mathrm{GGBS})$ cementitious blends in which a proportion part of $\mathrm{PC}$ was partially replaced with the mineral admixtures. The binary mixture (F70) was prepared by interchanging PC by FA at replacement level of $70 \%$, by weight, of the total binder content. The ternary mixtures (F60S10, F50S20, F60G10 and F50G20) were prepared by either FA and SF or FA and GGBS, where FA was partially replaced with 10 and $20 \%$. The quaternary mixtures (F60S5G5 and F50S10G10) were prepared by FA, SF and GGBS blends, where FA was partially replaced by 10 and $20 \%$. However, the mixture proportions are summarized in Table 2 in which the mixtures were designated according to the type and the amount of the cementitious materials included.

\subsection{Methods}

The mixing process was kept constant to supply the same homogeneity and uniformity in all mixtures. It starts by mixing all of powder and sand for a minute using pan mixer. Then, three quarters of the mixing water was added and mixed for an additional $2 \mathrm{~min}$. Coarse aggregate was subsequently added to the rotating mixer and mixing was continued for further $2 \mathrm{~min}$. Thereafter, the HRWR with remaining water was added and the mixture was mixed for an additional 3 min until the mixture became homogenous. Cubes of $100 \mathrm{~mm}$ side long moulds comply with BS 1881 and moulds of $71 \times 71 \times 30 \mathrm{~mm}$ comply with ES: $269-2 /$ 2003 were cast and vibrated for $1 \mathrm{~min}$ to remove air bubbles. Twenty four hours after casting, the specimens were demolded and cured in water till the age of testing.

In hardened state, cubes were tested in compression at ages of 7, 28, 90 and 180 days according to BS 1881: Part 116: 1983 (British Standards Institution 1983). Abrasion resistance was carried out at ages of 7, 28, 90 and 180 days according to Egyptian Standard specifications ES: 269-2/ 2003 (2003). In compliance with ES: 269-2/2003, the abrasion system had a steel disc, which had a diameter of $750 \mathrm{~mm}$ and rotating speed of $30 \pm 1 \mathrm{cycle} / \mathrm{min}$, a counter and a lever, which could apply $294 \pm 3 \mathrm{~N}$ on the specimens. Abrasion test apparatus is shown in Fig. 2. In the test procedure, $20 \pm 0.5 \mathrm{~g}$ of wear dust (corundum crystalline $\mathrm{Al}_{2} \mathrm{O}_{3}$ ) was spread on the disc, the specimens were then placed, the load was applied to the specimen and the disc was rotated for four periods, whilst a period was equal to 22 revolutions. After that, the surfaces of the disc and the sample were cleaned by the brush then new $20 \pm 0.5 \mathrm{~g}$ 
Table 2 Concrete mixture proportions.

\begin{tabular}{|c|c|c|c|c|c|c|c|}
\hline \multirow{2}{*}{$\begin{array}{c}\text { Mixture } \\
\text { Designation }\end{array}$} & \multicolumn{7}{|c|}{ Ingredient $/ \mathrm{m}^{3}$} \\
\hline & $\mathrm{PC}(\mathrm{kg})$ & FA $(\mathrm{kg})$ & $\mathrm{SF}(\mathrm{kg})$ & GGBS (kg) & $\mathrm{CA} /$ sand $^{\mathrm{a}}(\mathrm{kg})$ & $w / b$ & HRWR (1) \\
\hline F0 & 400 & 0 & 0 & 0 & 1.8 & 0.4 & 8 \\
\hline F70 & 120 & 280 & 0 & 0 & 1.8 & 0.4 & 8 \\
\hline F60S10 & 120 & 240 & 40 & 0 & 1.8 & 0.4 & 8 \\
\hline F50S20 & 120 & 200 & 80 & 0 & 1.8 & 0.4 & 8 \\
\hline F60G10 & 120 & 240 & 0 & 40 & 1.8 & 0.4 & 8 \\
\hline F50G20 & 120 & 200 & 80 & 0 & 1.8 & 0.4 & 8 \\
\hline F60S5G5 & 120 & 240 & 20 & 20 & 1.8 & 0.4 & 8 \\
\hline F50S10G10 & 120 & 200 & 40 & 40 & 1.8 & 0.4 & 8 \\
\hline
\end{tabular}

${ }^{a}$ Coarse aggregate to sand ratio by weight.

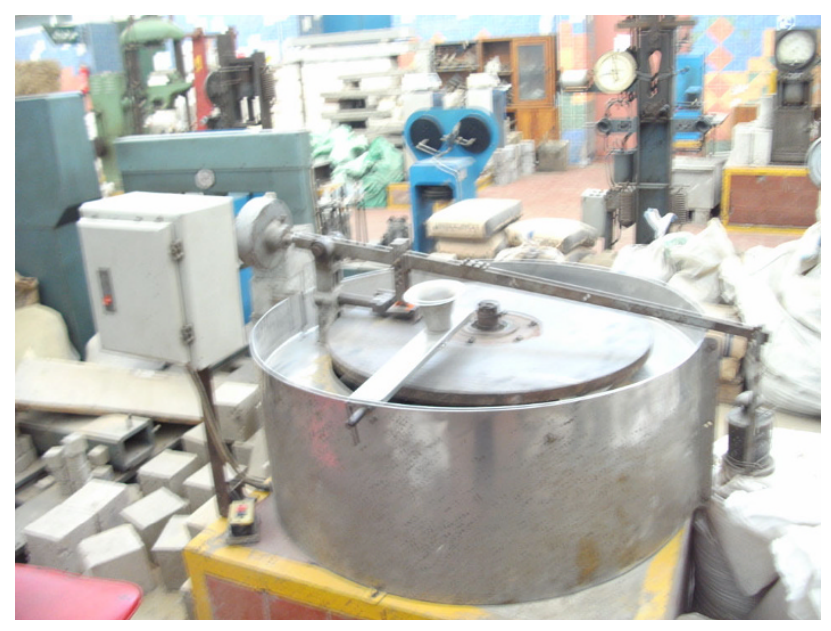

Fig. 2 Abrasion test apparatus.

standard abrasive dust is placed and the specimens were rotated $90^{\circ}$ in the horizontal axis. The above-mentioned procedure was repeated for 16 periods (i.e., the specimens were submitted to a $16 \times 22$ revolutions) by rotating the specimens $90^{\circ}$ in each period. Thickness measurements of the specimens also have been done from three points. The abrasion thickness loss can be calculated from:

$$
A=\frac{\left(W_{0}-W_{1}\right)}{W_{0}} \frac{V}{S},
$$

where $A(\mathrm{~mm})$ is the average abrasion thickness loss, $W_{0}$ (g) and $W_{1}(\mathrm{~g})$ are the initial and final weight of the specimen, $V\left(\mathrm{~mm}^{3}\right)$ is volume and $S\left(\mathrm{~mm}^{2}\right)$ is surface of the specimen.

At age of 28 days, after the compressive strength/abrasion resistance test, selected debris from the crushed samples were stored in acetone for 3 days in order to stop the hydration. The debris was then filtered from the acetone and dried in the desiccators under vacuum. Part of the dried samples was ground in an agate mortar. Particles passing a $63 \mu \mathrm{m}$ sieve were used for XRD. Some selected pieces were also used for the scanning electron microscopy (SEM) analysis.

\section{Results and Discussion}

\subsection{Compressive Strength}

From here on, the term "slag" will refer to (GGBS). However, the compressive strength development for all concrete mixtures is presented in Fig. 3. There is a noticeable decrease in compressive strength when PC was partially replaced with $70 \%$ FA (F70) during 7, 28, 90 and 180 days of hydration. The highest reduction in compressive strength was observed at 7 days of hydration which reached $71.02 \%$. It can be noted from Fig. 3 that as curing time increases as the reduction in compressive strength between F0 and F70 decreases. The reductions in compressive strengths due to the inclusion of $70 \%$ FA were $66.46,49.43$ and $38.42 \%$ at ages of 28, 90 and 180 days, respectively. The results of strength values at 90 and 180 days indicated that there was continuous and significant improvement in strength beyond the age of 28 days. The increase in strength from 28 to 90 days was $82.39 \%$, whereas the increase in strength from 28 to 180 days was $143.43 \%$. The increase in strength is due to the cement that continued to hydrate. The lower compressive strength in F70 specimens, especially at early age, is due to the weak interfacial zone between the aggregate and HVFA paste (Jiang 1999) and due to the slow pozzolanic reaction of FA (low-calcium) and the dilution effect is dominant especially during the early ages, with only a few parts of the FA participating in the reaction (Jiang and Guan 1999). Similar results, at 28 days, were reported elsewhere (Atiş 2003b; Lammertijn and De Belie 2008; Durán-Herrera et al. 2011). However, after 7 days of hydration Güneyisi and Gesoğlu (2008) found the reduction in mortar compressive strength due to the inclusion of $60 \%$ FA was about $71.58 \%$ whilst Atiş (2005) found $64.46 \%$ reduction in roller concrete compressive strength due to replacing cement with $70 \%$ FA. Other authors as Baert et al. (2008) found $35 \%$ reduction in concrete compressive strength, at 91 days, due to replacing cement with $60 \%$ FA, whilst Gesoğlu et al. (2009) found $40 \%$ reduction in concrete compressive strength, at 90 days, due to replacing cement with $60 \%$ FA. 


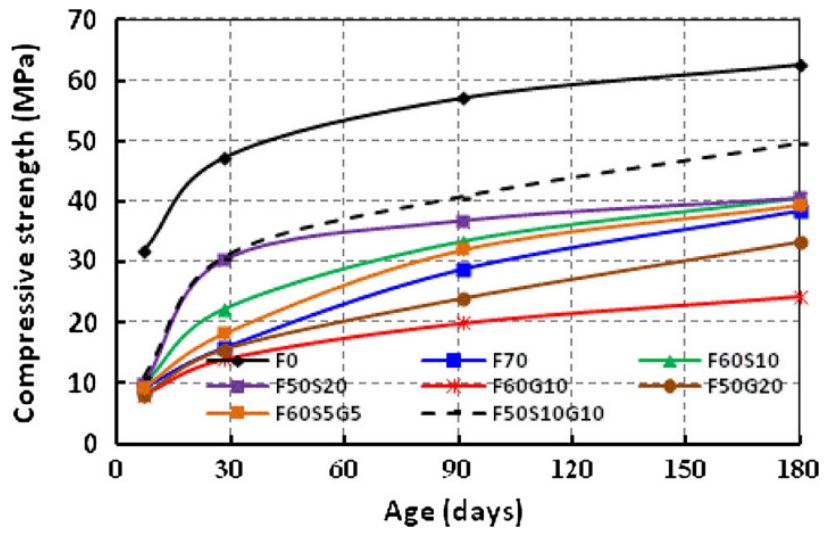

Fig. 3 Compressive strength development.

The influence of replacing part from FA with SF at levels of 10 and $20 \%$ on compressive strength values is shown in Fig. 3. The enhancements in strength depend on the content of SF in the HVFA concrete matrix. As shown in Fig. 3, when $60 \% \mathrm{FA}$ incorporated with $10 \% \mathrm{SF}$, the compressive strength is markedly increased at all ages. The enhancement in strength was $5.8 \%$ at 7 days, related to F70, whilst it reached $40 \%$ at 28 days. However, the enhancements in strengths of F60S10 over those of F70 were 15 and $4.4 \%$ at ages of 90 and 180 days, respectively. Increasing the dosage of SF from 10 to $20 \%$ with combination of $50 \%$ FA led to further increasing in compressive strength values at all ages. The increases in compressive strengths were 107.6, 191.4, 127.4 and $105.1 \%$ at ages of $7,28,90$ and 180 days, respectively, relative to $\mathrm{F} 70$.

Replacing part of FA with equally combinations of SF and slag, led to marginal increases in compressive strengths at $10 \%$ replacement and significant increases in compressive strengths at $20 \%$ replacement. The increases in compressive strengths at replacement level of $10 \%$ were $100.9,114.8$, 110.8 and $102.1 \%$ at ages of $7,28,90$ and 180 days, respectively, whilst they were 118.2, 193.9, 140.9 and $128.4 \%$ at replacement level of $20 \%$, respectively. Other previous author (Yazici 2008) reported that the inclusion of SF in HVFA concrete had positively affected the compressive strength. Zhang et al. (2011) partially replaced cement in concrete with $15 \% \mathrm{FA}$, in addition, part of the cement was replaced with SF at levels of 3, 6, 9 and $12 \%$. The results indicated that as the content of SF increased as the compressive strength of concrete increased at ages of 3,7 and 28 days. Rashad et al. (2009) partially replaced $20 \%$ of cement with individual FA and equally combination of SF and FA. They reported that the compressive strength of (SF + FA) concrete mixtures was higher than that of FA concrete mixtures at ages of 28,90 and 365 days. Toutanj et al. (2004) concluded that the combination of different supplementary materials increased concrete compressive strength. They investigated combination of $10 \% \mathrm{SF}, 25 \%$ slag, $15 \%$ FA and $50 \%$ cement, and found an increase in strength about $22 \%$ over the control mixture (with neat cement) at age of 14 days. On the other hand, Nassif et al. (2005) reported that there was adverse effect on concrete compressive strength when $10 \%$ SF blended with $20 \%$ FA and $70 \%$ PC compared with $30 \% \mathrm{FA}+70 \% \mathrm{PC}$ at ages from 1 up to 90 days.

In general, SF is very reactive pozzolanic material because of its extreme fineness and very high amorphous silicon dioxide content. The mechanism of SF in concrete can be described basically under the following roles: pore-size refinement and matrix densification; cement paste-aggregate interfacial refinement; and reaction with free-lime (Rafat 2001). However, the enhancement in the compressive strengths of hardened HVFA concretes due to the inclusion of SF may be related to the packing effect of the fine SF which acts as filler which fill in voids among FA and cement, resulting in a compacted system, thus the compressive strength values enhanced and increased. Further, the particles of SF are also served as the nucleation sites of hydration reaction, which promotes the reaction rate and the formation of hydration products (Rashad and Khalil 2013). Moreover, the fine SF caused significant improvements in the distribution of pore size and pore shape of the matrix where pore size distribution has been found to be one of the major factors affecting strength development (Taylor 1997). It is worth mentioning that the SF has a high pozzolanic effect. SF contains about $96.1 \% \mathrm{SiO}_{2}$ as shown in Table 1 . These rezones make the HVFA concrete containing SF stronger than HVFA concrete without SF.

For F60G10 and F50G20 series, the compressive strengths of these series seemed to be lower than that of F70. The inclusion of $10 \%$ slag with $60 \%$ FA caused a reduction in compressive strengths at all ages, relative to F70. The reduction in strength increased as the concrete age increased. These reductions were $11.89,30.79$ and $36.64 \%$ at ages of 28, 90 and 180 days, respectively. The lowest compressive strength of $8.04 \mathrm{MPa}$ was obtained, at age of 7 days. Increasing the FA replacement level with slag from 10 to $20 \%$ led to a reduction in the compressive strength gap between F60G10 and F70. The reductions in compressive strengths, related to F70, were 11.81, 0.9, 16.56 and $13.27 \%$ at ages of 7, 28, 90 and 180 days, respectively. These reductions in compressive strengths may be related to the lower specific surface area of the used slag compared to FA. However, some studies showed that slag is slowly reactive (Swamy 1990) and the addition of slag retarded the setting time of concrete (Hogan and Meusel 1981). The results of compressive strength values that obtained by Kuder et al. (2012) indicated that concretes containing $60 \%$ FA gave lower strength values than that containing $45 \%$ FA combined with $15 \%$ slag at age of 7 days, whilst concrete containing $80 \%$ FA gave higher strength values than that containing $60 \%$ FA combined with $20 \%$ slag at ages of 7 , 14, 28 and 56 days. It worth mentioning that Rashad et al. (2009) reported that when cement was partially replaced with 10 and $20 \%$ with either slag or FA, the compressive strength of slag concretes was lower than that of FA concrete mixtures at ages of 7,90 and 365 days. They also reported that the concrete compressive strength of $20 \%$ (from cement weight) of equally combination of FA and slag was lower than that of the individual FA at ages of 7, 90 and 365 days. 


\subsection{Abrasion Resistance}

First of all, when concretes were tested for abrasion resistance, similar findings to those of the compressive and splitting tensile strengths were recorded. Further, abrasion test results indicated that the compressive strength was an important factor affecting the abrasion resistance of concrete as well as splitting tensile strength, such that the higher the strength is, the higher the abrasion resistance of concrete will be. However, the abrasion resistance test was performed at ages of 7, 28, 90 and 180 days for all concrete mixtures. In general, the depth of abrasion of concrete mixtures decreased with age (Figs. 4, 5, 6). This was primarily attributed to the increase in compressive strength resulting from increasing the maturity of each concrete mixture. From Figs. 4, 5 and 6 it can be seen that abrasion resistance of both HVFA and HVFA blends concrete mixtures was lower than that of the F0 mixture at all ages.

Figure 4 shows that the abrasion resistance of F0 was sharply lowered with the inclusion of $70 \% \mathrm{FA}$, as cement replacement (F70). The F70 exhibited sharply decreasing in wear depth from 7 up to 90 days. Beyond 90 days, F70 showed gradually decreasing in wear depth. On the other hand, the F0 exhibited sharply decreasing in wear depth from 7 up to 28 days, then gradually trend decreasing in wear depth was observed. At age of 90 days, the abrasion

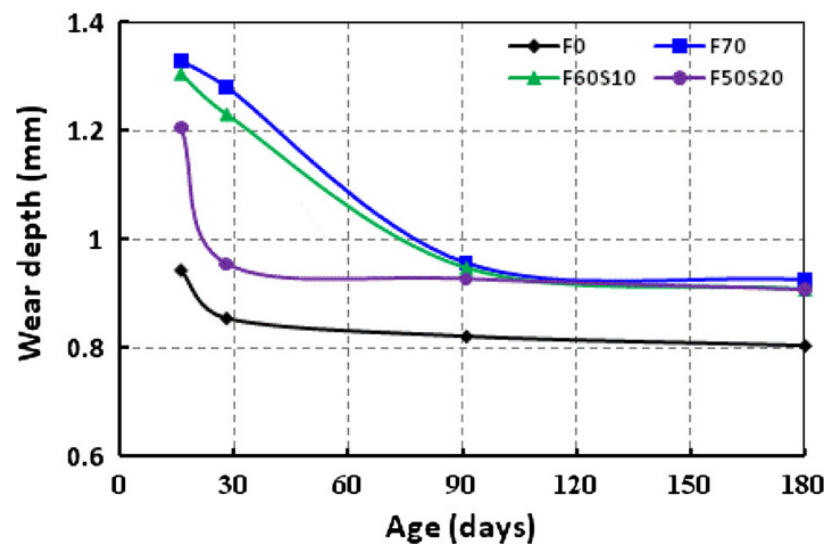

Fig. 4 Wear depth of F0, F70, F60S10 and F50S20 versus age.

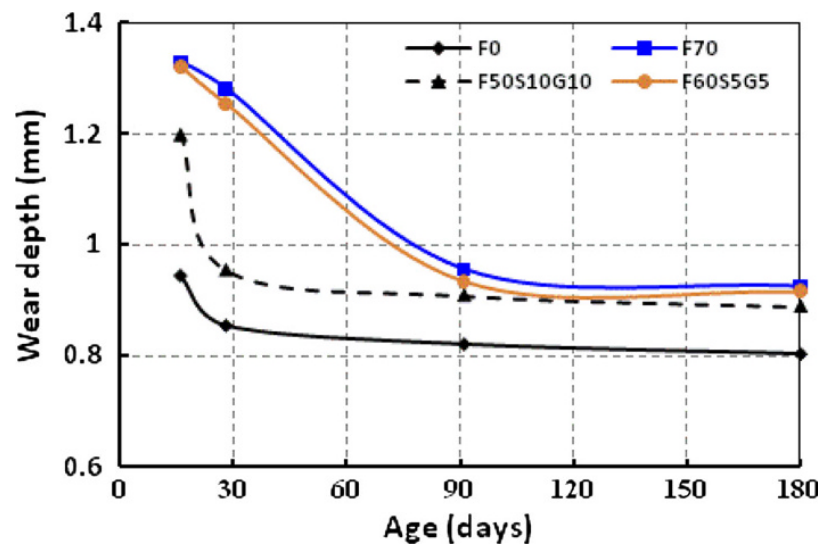

Fig. 5 Wear depth of F0, F70, F50S10G10 and F60S5G5 versus age. resistance of F70 is partially comparable to that of F0 at 7 days, whilst the abrasion resistance of F70 at age of 180 days is higher than that of F0 at age of 7 days. Replacing part of FA with $10 \%$ SF (F60S10), resulting improving in abrasion resistance at all ages, compared to F70. The most pronounced increasing in abrasion resistances was observed at ages of 7 and 28 days. Beyond 28 days, marginal increases in abrasion resistance were observed. Further increase in SF content from 10 to $20 \%$ (F50S20) led to further increase in abrasion resistance. As shown in Fig. 4, the wear depth versus hydration time of F50S20 shows the same trend of F0 where significant decreasing in wear depth from 7 to 28 days, then gradually decreasing in wear depth beyond 28 days was observed. It can be noted from Fig. 4 that the abrasion resistance of F50S20 at 28 days is comparable to that of F0 at 7 days. Compared to F70, there is a significant improving in abrasion resistance especially at ages of 7 and 28 days, where wear depth of F70 at 28 days was about 1.34 times that of F50S20, whilst it reached only 1.02 times at age of 180 days. It can be noted that the abrasion strength of F50S20 is comparable to that of F60S10 at age of 180 days. It can be concluded from Fig. 4 that as the SF content increases as the abrasion resistance increases (i.e., the wear depth decreases).

Figure 5 shows the wear depth versus hydration time of F60S5G5 and F50S10G10 compared to F0 and F70. The inclusion of $10 \%$ of equally combination of SF and slag led to marginal improvements in abrasion resistance at all ages, relative to $\mathrm{F} 70$. Comparing the abrasion resistance of F60S5G5 with that of F60S10 which presented in Fig. 4, it can be noted that there is a slightly decreasing in abrasion resistance of F60S5G5 compared to F60S10. Increasing the replacement level up to $20 \%$, with equally combination of SF and slag (F50S10G10), led to sharply increasing in abrasion resistance. The wear loss versus hydration time trend of F50S10G10 seemed to be similar of that of F0 and F50S20. Apparently from Fig. 5 its clear noted that the abrasion resistance of F50S10G10 at 180 days is higher than that of F0 at age of 28 days. Comparing the wear loss of F50S10G10 with that of F50S20 which presented in Fig. 4, it can be observed that F50S10G10 gave slightly higher

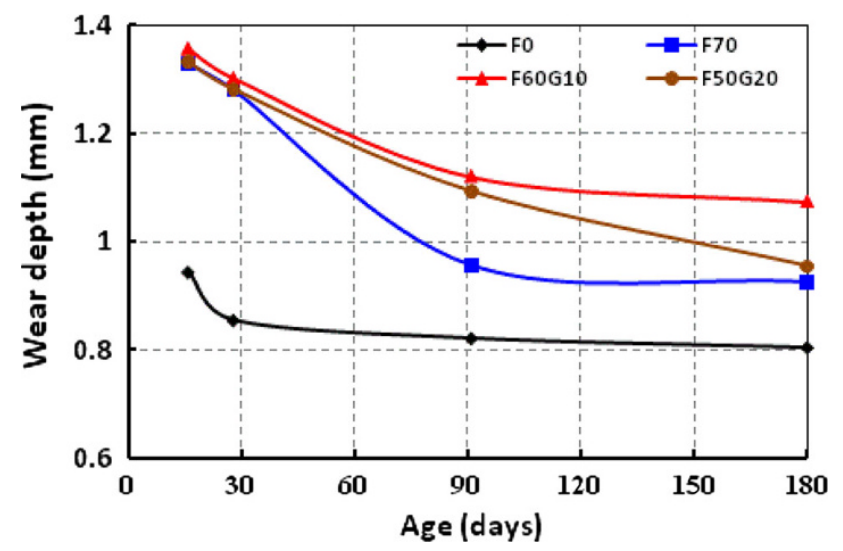

Fig. 6 Wear depth of F0, F70, F60G10 and F50G20 versus age. 
abrasion resistance than F50S20. Indeed, regardless of F0, F50S10G10 gave the highest abrasion resistance.

In the literature, some authors reported that the inclusion of SF increased the concrete/mortar abrasion resistance. Turk and Karatas (2011) studied the abrasion resistance of self compacted concrete in which cement was partially replaced with FA or SF. The replacement levels of FA were 25, 30, 35 and $40 \%$, whilst they were 5, 10, 15 and $20 \%$ for SF. They reported that SF concretes gave better abrasion resistance than FA concretes. The abrasion resistance increased as SF content increased up to $15 \%$, whilst the abrasion resistance decreased with increasing FA content. Liu (2007) partially replaced cement in concrete with SF at levels of 5 and $10 \%$. The waterborne abrasion over a large area of the tested slab was developed to investigate the influence of surface cracks on the abrasion resistance of concretes. The results indicated that the abrasion resistance increased with the increase in SF content.

Figure 6 shows the wear depth versus hydration time of F60G10 and F50G20 compared to F0 and F70. However, replacing part of FA with $10 \%$ slag (F60G10) led to

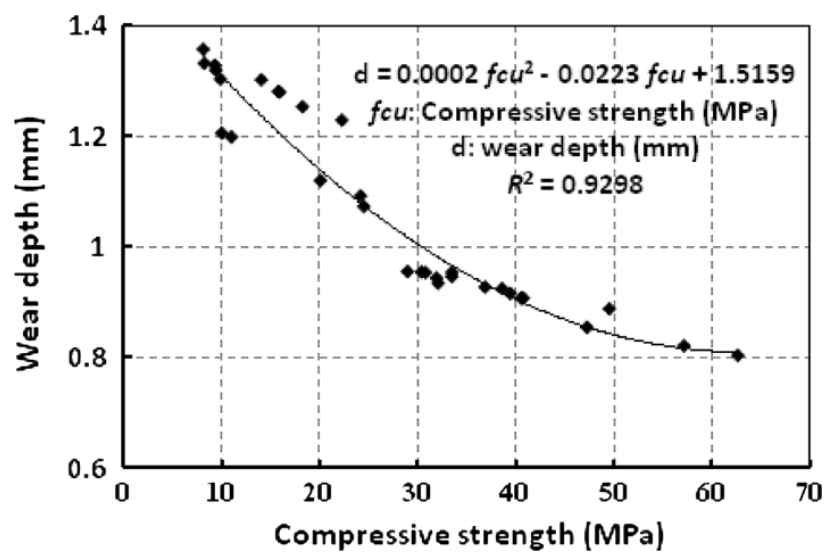

Fig. 7 Relationship between wear depth and compressive strength.

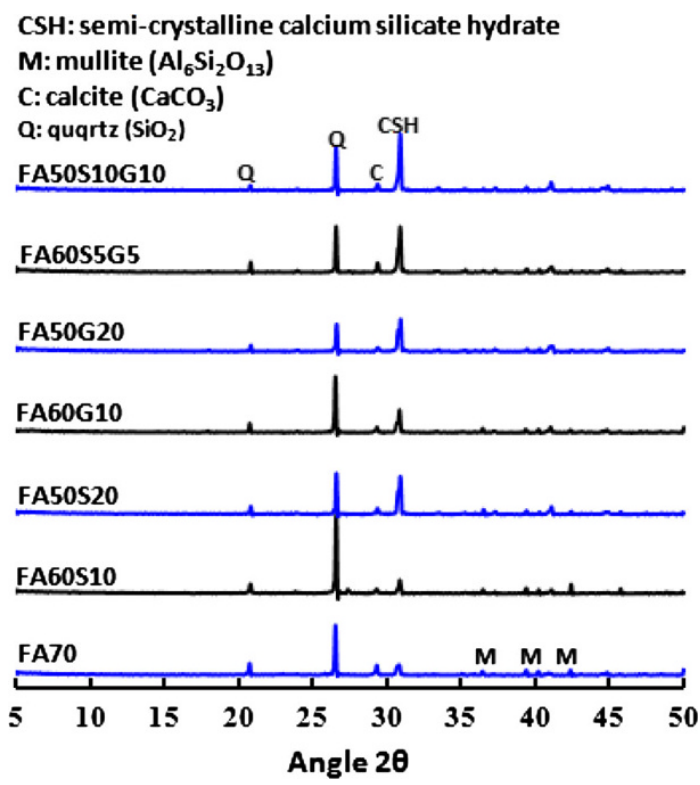

Fig. 8 XRD patterns of concretes at 28 days hydration. adversely effect on abrasion resistance of concrete. The abrasion resistances of F60G10 not only lower than that of F0, but also lower than those of F70. The abrasion resistances of F60G10 account the lowest abrasion resistance of the studied concrete mixtures. Obviously form Fig. 6 it can be noted that the abrasion resistance of F60G10 at 180 days is lower than that of F70 at 90 days. Increasing the dosage of slag from 10 to $20 \%$ (F50G20) led to marginal improving in abrasion resistance at ages of 7,28 and 90 days and significant improving in abrasion resistance at age of 180 days, compared to F60G10. The abrasion resistance of F50G20 is still lower than that of F70 at all ages. In the literature some authors reported that the inclusion of slag decreased the abrasion resistance of the matrix where Yetgin and Çavdar (2011) studied the effects of some additives as SF, blast furnace slag, FA, natural pozzolan and limestone on the abrasion resistance of mortars. $W / b$ ratio was constant for all mortar mixtures at 0.5 . Abrasion of the mortar mixtures were evaluated after curing in tap water for six different periods throughout 1 year. The Bohme apparatus was used during abrasion tests. The results indicated that the increase of clinker, limestone and SF ratios increased the abrasion resistance at the end of the year, whilst blast furnace slag, natural pozzolan and FA conversely affected the abrasion resistance.

Figure 7 shows the relation between depth of wear and compressive strength of all concrete mixtures regardless of pozzolan content and curing time. It is abundantly clear from this figure that the abrasion resistance of concrete is closely related with compressive strength. The figure clearly shows that the depth of wear decreases as compressive strength increases. This mean that the compressive strength is the most important factor governing the abrasion resistance of concrete (Naik et al. 1995) and the abrasion resistance of concrete follows its compressive strength (Atiş 2002, 2003a; Mehta 1986; Hui 2006; Rashad 2013; Naik et al. 1994; Hadchti and Carrasquillo 1988; Laplante and Aïfcin 1991; Gjorv et al. 1990). However, Fig. 7 illustrates that a best-fit

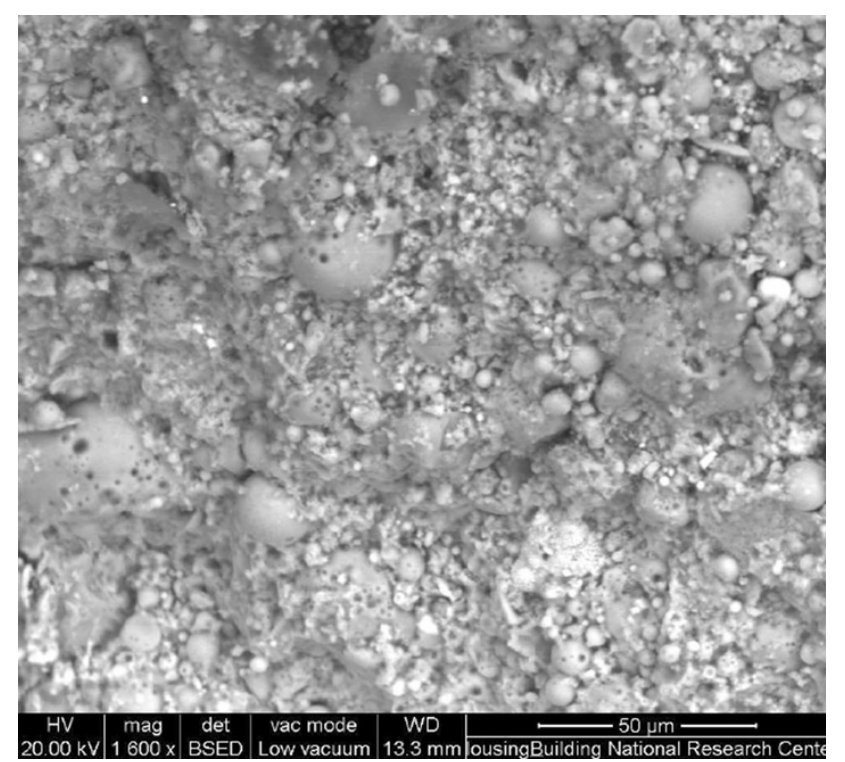

Fig. 9 SEM micrographs of fracture surface of hardened F70.

76 | International Journal of Concrete Structures and Materials (Vol.8, No.1, March 2014) 


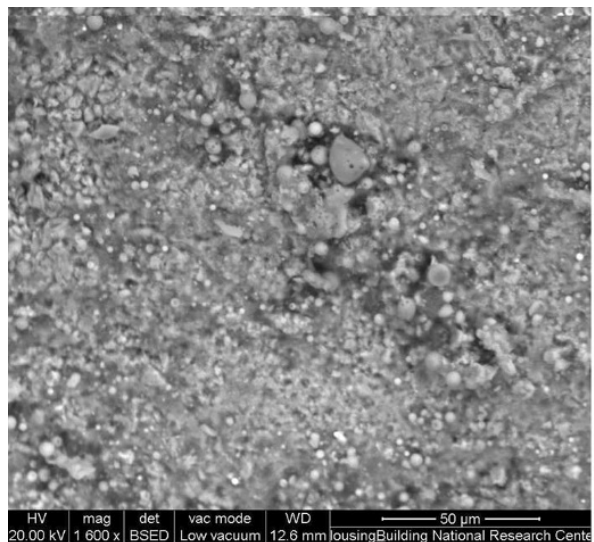

(a) $\mathrm{F} 60 \mathrm{~S} 10$

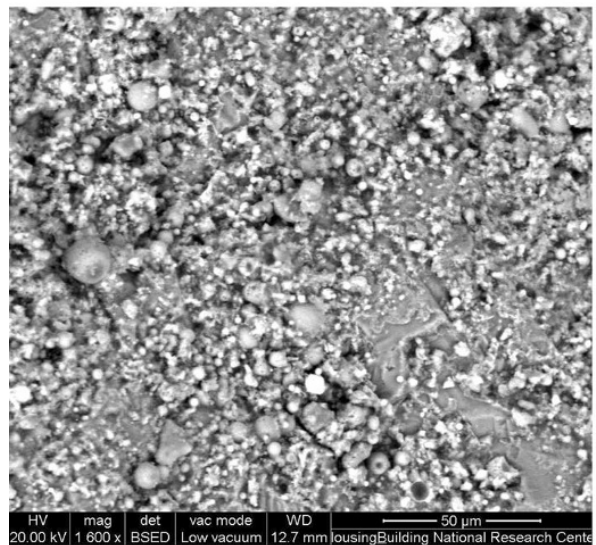

(c) F60G10

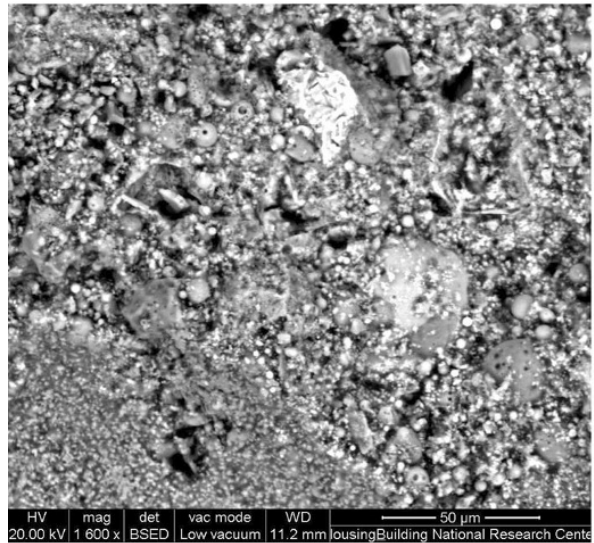

(e) F60S5G5

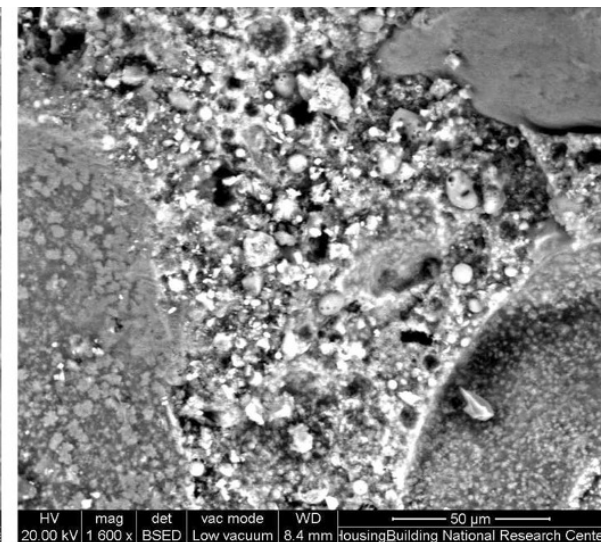

(b) F50S20

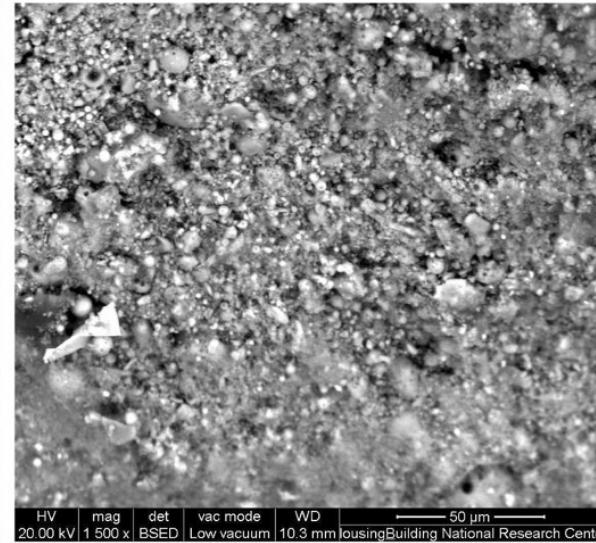

(d) F50G20

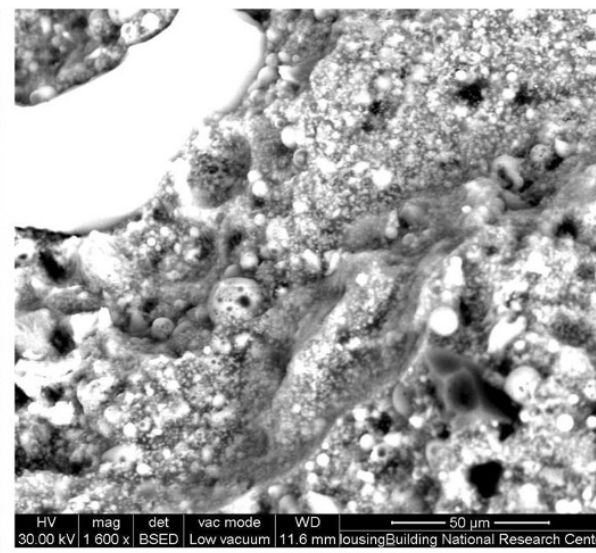

(f) $\mathrm{F} 50 \mathrm{~S} 10 \mathrm{G} 10$

Fig. 10 SEM micrographs of fracture surface of hardened blended HVFA concretes.

equation is derived by second order polynomial regression of all data points in the figure. The correlation coefficient (value of $R^{2}$ ) was very good (0.9298). Other authors (Horszczaruk 2005; Gurpreet and Rafat 2012) in the literature reported that the relation between compressive strength and abrasion resistance of concrete is polynomial. However, the best regression of the relation between compressive strength and abrasion resistance is still differ from author to another, where there are abundant numerals of authors believed that the relationship between compressive strength and abrasion resistance of concrete (Hui 2006; Rashad 2013; Naik et al. 1994, 2002; Yen et al. 2007; Ghafoori and Diawara 1999; Atiş et al. 2009) or mortar (Ahmet and Şükru 2010) is linear. Other authors (Kazim and Mehmet 2011;
Rafat and Khatib 2010; Siddique et al. 2012; Konin and Kouadio 2012) reported that the relation between abrasion resistance and compressive strength is power, whilst Atiş (2002) and Yen et al. (2007) pointed out that this relation is hyperbolic. Further, Siddique (2010) reported that this relation is logarithmic, whilst Horszczaruk (2005) and Singh and Siddique (2012) reported that this relation is polynomial. Ghafoori and Sukandar (1995) reported that the relationship between compressive strength and abrasion resistance of concrete is quadratic form. On the other hand, other authors (Atiş and Çelik 2002) reported that the relation between flexural tensile strength and abrasion resistance was stronger than the relation between compressive strength and abrasion resistance regarding to the pozzolanic reactions of FA as 
well as the distinct nature of spaghetti-like (Mehta 1986; Neville 1995) hydration production of hydrated FA and cement paste.

\subsection{Crystalline Phases}

Figure 8 presents XRD traces of HVFA and blended HVFA concrete samples at age of 28 days. The quartz $\left(\mathrm{SiO}_{2}\right)$ and mullite $\left(\mathrm{Al}_{6} \mathrm{Si}_{2} \mathrm{O}_{13}\right)$ in the initial FA were appeared in all samples. The calcite $\left(\mathrm{CaCO}_{3}\right)$ and semicrystalline calcium silicate hydrate $(\mathrm{CSH})$ were also detected in all samples. The XRD of all samples do not contain portlandite $(\mathrm{CH})$. This means that the FA consumed the portlandite. Evidently from Fig. 8 the sample incorporated $70 \%$ FA shows smaller peak intensity of semi-crystalline CSH compared to that of F50S20, F50G20, F60S5G5 and F50S10G10 samples. The lower intensity of this peak may be a part of the reason why lower compressive strength and abrasion resistance obtained in F70 compared to those mixtures. Apparently from Fig. 8 the sample incorporated $50 \%$ FA plus $10 \%$ SF plus $10 \%$ slag (F50S10G10) shows the highest peak intensity of semi-crystalline $\mathrm{CSH}$. This may be a part of the reason why F50S10G10 gave the highest compressive and abrasion resistance of the blended HVFA mixtures.

\subsection{Morphology and Microstructural Analysis}

Investigations of the microstructure of the hardened concrete samples using SEM have distinct changes in morphology as a consequence of pozzolan type and its content. Figure 9 shows micrographs of fracture surface of F70 at age of 28 days. As shown from this figure, the sample is dominated by FA particles which are spherical. These hollow spheres are known as cenospheres. This sample seemed to appear great deals of partly un-reacted and un-reacted FA particles (retaining their smooth and spherical shape are distinguishable) coated with hydration product (i.e. CSH) or relicts of hydrated particles. Some pores could be observed (at upper right and upper left).

Figure 10 gives the SEM micrographs of HVFA concrete samples blended with SF, slag and their combinations after 28 days of hydration. With respect to the $70 \%$ FA sample, which shown in Fig. 9, a reduction in the apparent porosity can be observed in F60S10 and F50S20 samples (Fig. 10a, b) and the matrix looks more continuous and compact. This may be a part of the reason why higher compressive strength was obtained for blended HVFA concretes with SF as compared to F70. The microstructure of F50S20 sample (Fig. 10b) showed little un-reacted particles compared to F60S10 sample which shown in Fig. 10a.

The microstructure of the hardened HVFA concrete samples blended with slag at levels of 10 and $20 \%$ are shown in Fig. 10c, d. Un-reacted FA and slag particles can be observed. The FA and slag un-reacted particles are readily distinguished by their geometry; FA is comprised of polydisperse spherical particles, whereas slag is visible as irregular jagged particles (Duxson and Provis 2008) or sharply angular (Escalante-García and Sharp 2001). Some porous can be observed intermixed with dense reaction products. However, for both FA and slag particles, the reaction occurs predominantly at particle surface, consuming the precursor material and forming a porous partially-reacted layer (Lloyd et al. 2009). It is clearly appear from Fig. 10c, d that the microstructure of the sample containing higher amount of slag (F50G20) seemed to be denser than that containing lower amount of slag (F60G10) due to increasing formation of $\mathrm{CSH}$ gel.

Figure 10e, f show the microstructures of concrete samples incorporating equally combinations of SF and slag at total levels of 10 and $20 \%$, respectively. The reaction products formed is much more compact, homogeneous and uniform when compared to the concrete sample with $70 \%$ FA (F70). A lower replacement of FA by equally combination of SF and slag (F60S5G5) is found to create a microstructure that is more porous than that in a F50S10G10 (Fig. 10e, f). This shows that the use of more FA replacement levels with equally combinations contents of both SF and slag increases the amount of reaction products formation, and consequently reduces the porosities and increases the compressive strength and abrasion resistance. It is worth mentioning that the microstructure of F50S10G10 (Fig. 10f) seemed to be similar to that of F50S20 (Fig. 10b).

\section{Conclusions}

In this investigation the compressive strength and abrasion resistance of PC concrete, HVFA concrete and HVFA concrete blends with SF and slag were studied. The inclusion of FA was $70 \%$ as cement replacement; then 10 and $20 \%$ from FA was partially replaced with individual SF, individual slag and equally combinations of SF and slag. The following conclusions are drawn from this investigation:

(1) Abrasion resistance of concrete was strongly influenced by its compressive strength, irrespective of pozzolan content.

(2) Both compressive strength and abrasion resistance decreased with the incorporation of $70 \%$ FA compared to F0, especially at early age. The reduction rate decreased as curing time progressed.

(3) Irrespective of F0, incorporation $20 \%$ of equally combination of SF and slag (i.e. $10 \% \mathrm{SF}$ and $10 \%$ slag) in HVFA concrete gave the highest compressive strength and abrasion resistance at all ages where the abrasion resistance of F50S10G10 at age of 28 days was comparable to that of F0 at age of 7 days, whilst the abrasion resistance of F50S10G10 at age of 180 days was higher than that of F0 at age of 28 days.

(4) The incorporation of $20 \%$ SF gave good compressive strength and abrasion resistance and came in the second place, incorporation of $10 \% \mathrm{SF}$ came in the third place and incorporation of $10 \%$ of equally combination of SF and slag (i.e. $5 \% \mathrm{SF}$ and $5 \%$ slag) came in the fourth place. 
(5) Adversely effect of incorporation of either 10 or $20 \%$ slag, as individual, in HVFA concrete on both compressive strength and abrasion resistance. The inclusion of $10 \%$ slag gave the lowest compressive strength and abrasion resistance at all ages where the abrasion resistance of F60G10 at age of 180 days was still lower than that of F70 at age of 90 days.

(6) HVFA and HVFA blends concrete mixtures exhibited substantially higher rates of compressive strength and abrasion resistance gain as compared with the reference concrete mixture (F0).

(7) It is recommended to blend HVFA concrete with individual SF or with equally combination of SF and slag to improve compressive strength and abrasion resistance.

(8) It is not recommended to blend HVFA concrete with individual slag because it gave adversely effect on compressive strength and abrasion resistance.

(9) HVFA concrete can be used in the field where high abrasion resistance of concrete is required, providing that proper mixture design is used and trials are carried out.

\section{Open Access}

This article is distributed under the terms of the Creative Commons Attribution License which permits any use, distribution, and reproduction in any medium, provided the original author(s) and the source are credited.

\section{References}

Atiş, C. D. (2002, May/June). High volume fly ash abrasion resistant concrete. Journal of Materials in Civil Engineering, 274-277.

Atiş, C. D. (2003a, July/August). Abrasion-porosity-strength model for fly ash concrete. Journal of Materials in Civil Engineering, ASCE, 408-410.

Atiş, C. D. (2003b, March/April). High-volume fly ash concrete with high strength and low drying shrinkage. Journal of Materials in Civil Engineering, ASCE, 153-156.

Atiş, C. D. (2005). Strength properties of high-volume fly ash roller compacted and workable concrete, and influence of curing condition. Cement and Concrete Research, 35, 1112-1121.

Atiş, C. D., \& Çelik, O. N. (2002). Relation between abrasion resistance and flexural strength of high volume fly ash concrete. Materials and Structures, 35, 257-260.

Atiş, C. D., Karahan, O., Ari, K., Sola, Ö. C., \& Bilim, C. (2009, August). Relation between strength properties (flexural and compressive) and abrasion resistance of fiber (steel and polypropylene)-reinforced fly ash concrete. Journal of Materials in Civil Engineering, ASCE, 402-408.

Baert, G., Poppe, A.-M., \& De Belie, N. (2008). Strength and durability of high-volume fly ash concrete. Structural Concrete, 9(2), 101-108.
Barrow, R. S., Hadchiti, K. M., Carrasquillo, P. M. \& Carrasquillo, R. L. (1989). Temperature rise and durability of concrete containing fly ash. In Proceedings of CANMET/ ACI Third International Conference on the Use of Fly Ash, Silica Fume, Slag and Natural Pozzolans in Concrete, Trondheim, Norway (Vol. 1, pp. 331-348).

Bilodeau, A., \& Malhotra, V. M. (1992a). Concrete incorporation high volume of ASTM Class F fly ashes, mechanical properties and resistance of deicing salt scaling and chloride-ion penetration. In Fly ash, silica fume, slag and normal pozzolans in concrete, Proceedings Fourth International Conference, Istanbul, Turkey (pp. 319-349), 3-8 May 1992.

Bilodeau, A., \& Malhotra, V. M. (1992b). Concrete incorporating high volume of ASTM Class F fly ashes: Mechanical properties and resistance of deicing salt scaling and chloride-ion penetration. In V. M. Malhotra (Ed.), Proceedings of the CANMET/ACI Fourth International Conference on the Use of Fly Ash, Silica Fume, Slag and Natural Pozzolans in Concrete, Istanbul, Turkey, SP-132 (Vol. 1, pp. 310-349). Detroit, MI: American Concrete Institute.

Bouzoubaâ, N., Zhang, M. H., \& Malhotra, V. M. (2001). Mechanical properties and durability of concrete made with high-volume fly ash blended cements using a coarse fly ash. Cement and Concrete Research, 31, 1393-1402.

British Standards Institution, BS 1881-116:1983. (1983). Method for determination of compressive strength of concrete cubes. London, U.K.: BSI.

Carette, G. G., Bilodeau, A., Cheurier, R., \& Malhotra, V. M. (1992). Mechanical properties of concrete incorporating high volumes of fly ash from sources in the U.S. In Supplemental Proceedings of the CANMET/ACI Fourth International Conference on the Use of Fly Ash, Silica Fume, Slag and Natural Pozzolans in Concrete (pp. 1-33). EPRI Report No. TR-100577, March 1992.

Çavdar, A., \& Yetgin, Ş. (2010). Investigation of abrasion resistance of cement mortar with different pozzolanic compositions and subjected to sulfate medium. Construction and Building Materials, 24, 461-470.

Dunstan, M. R. H., Thomas, M. D. A., Cripwell, J. B. \& Harrison, D. J. (1992). Investigation into the long-term in situ performance of high fly ash content concrete used for structural application. In Fly ash, silica fume, slag and normal pozzolans in concrete, Proceedings of the Fourth International Conference, Istanbul, Turkey (pp. 1-20), 3-8 May 1992.

Durán-Herrera, A., Juárez, C. A., Valdez, P., \& Bentz, D. P. (2011). Evaluation of sustainable high-volume fly ash concretes. Cement and Concrete Composites, 33, 39-45.

Duxson, P., \& Provis, J. L. (2008). Designing precursors for geopolymer cements. Journal of the American Ceramic Society, 91, 3864-3869.

ES: 269-2/2003 (2003). Testing methods of cement tiles, Egyptian Standardization. Cairo, Egypt: Egyptian Organization for Standardization and Quality.

Escalante-García, J. I., \& Sharp, J. H. (2001). The microstructure and mechanical properties of blended cements hydrated at 
various temperatures. Cement and Concrete Research, 31, 695-702.

Gelber, S. H., \& Klieger, P. (1986). Effect of fly ash on physical properties of concrete. In V. M. Malhotra (Ed.), Fly ash, silica fume, slag and natural pozzolans in concrete, SP-91 (Vol. 1, pp. 1-50). Detroit, MI: American Concrete Institute.

Gesoğlu, M., Güneyisi, E., \& Özbay, E. (2009). Properties of self-compacting concretes made with binary, ternary, and quaternary cementitious blends of fly ash, blast furnace slag, and silica fume. Construction and Building Materials, $23,1847-1854$

Ghafoori, N., \& Diawara, H. (1999, September-October). Abrasion resistance of fine aggregate replaced silica fume concrete. ACI Materials Journal, 96-M69, 559-567.

Ghafoori, N., \& Sukandar, B. M. (1995, January-February). Abrasion resistance of concrete block pavers. ACI Materials Journal, 25-34.

Gjorv, O. E., Baerland, T., \& Ronning, H. R. (1990). Abrasion resistance of high strength concrete pavements. Concrete International, 12(1), 45-48.

Güneyisi, E., \& Gesoğlu, M. (2008). Properties of self-compacting mortars with binary and ternary cementitious blends of fly ash and metakaolin. Materials and Structures, $41,1519-1531$.

Hadchti, K. M., \& Carrasquillo, R. L. (1988, August). Abrasion resistance and scaling resistance of concrete containing fly ash. Research Report 481-3 (p. 185). Center for Transportation Research, Bureau of Engineering Research, University of Texas at Austin.

Hogan, F. J., \& Meusel, J. W. (1981). Evaluation for durability and strength development of a ground granulated blast furnace slag. Cement Concrete Aggregates, 3, 40-52.

Horszczaruk, E. (2005). Abrasion resistance of high-strength concrete in hydraulic structures. Wear, 259, 62-69.

Jiang, L. (1999). The interfacial zone and bond strength between aggregates and cement pastes incorporating high volumes of fly ash. Cement and Concrete Composites, 21, 313-316.

Jiang, L., \& Guan, Y. (1999). Pore structure and its effect on strength of high-volume fly ash paste. Cement and Concrete Research, 29, 631-633.

Koksal, F., Altun, P., Yigit, I., \& Sahin, Y. (2008). Combined effect of silica fume and steel fiber on the mechanical properties of high strength concretes. Construction and Building Materials, 22, 1874-1880.

Konin, A., \& Kouadio, D. M. (2012). Mechanical and abrasion resistance of recycled aggregates concrete in relation to the cement content. Modern Applied Science, 6(1), 88-96.

Kuder, K., Lehman, D., Berman, J., Hannesson, G., \& Shogren, R. (2012). Mechanical properties of self consolidation concrete blended with high volumes of fly ash and slag. Construction and Building Materials, 34, 285-295.

Kumar, B., Tike, G. K., \& Nanda, P. K. (2007, October). Evaluation of properties of high-volume fly-ash concrete for pavements. Journal of Materials in Civil Engineering, ASCE, 906-911.

Lammertijn, S., \& De Belie, N. (2008). Porosity, gas permeability, carbonation and their interaction in high-volume fly ash concrete. Magazine of Concrete Research, 60(7), 535-545.
Langan, B. W., Joshi, R. C., \& Ward, M. A. (1990). Strength and durability of concrete containing $50 \%$ Portland cement replacement by fly ash and other materials. Canadian Journal of Civil Engineering, 17, 19-27.

Laplante, P., Aïfcin, P. C., \& Vezina, D. (1991). Abrasion resistance of concrete. Journal of Materials in Civil Engineering, 3(1), 19-30.

Li, H., Zhang, M.-H., \& Ou, J.-P. (2006). Abrasion resistance of concrete containing nano-particles for pavement. Wear, 260, 1262-1266.

Liu, T. C. (1981). Abrasion resistance of concrete. ACI Journal, Proceedings, 78(5), 341-350.

Liu, Y.-W. (2007). Improving the abrasion resistance of hydraulicconcrete containing surface crack by adding silica fume. Construction and Building Materials, 21, 972-977.

Lloyd, R. R., Provis, J. L., \& Van Deventer, J. S. J. (2009). Microscopy and microanalysis of inorganic polymer cements. 1: Remnant fly ash particles. Journal of Material Science, 44, 608-619.

Mehta, P. K. (1986a). Concrete structure, properties and materials. In Prentice-Hall international series in civil engineering and engineering mechanics (3rd ed., p. 450).

Mehta, P. K. (1986b). Concrete: Structure properties and materials. Englewood Cliffs, NJ: Prentice-Hall, Inc.

Mei, Z., \& Chung, D. D. L. (2002). Improving the flexural modulus and thermal stability of pitch by the addition of silica fume. Journal of Reinforced Plastics and Composites, 21(1), 91-95.

Naik, T. R., Ramme, B. W., \& Tews, J. H. (1992). Pavement construction with high-volume Class $\mathrm{C}$ and Class $\mathrm{F}$ fly ash concrete. In CANMET/ACI Fourth International Conference on the Use of Fly Ash, Silica Fume, Slag and Natural Pozzolans in Concrete, Istanbul, Turkey, May 1992.

Naik, T. R., \& Singh, S. S. (1991). Effects of inclusion of fly ash on abrasion resistance of concrete. In Proceedings of the Second CANMETIACI Conference on Durability of Concrete, Montreal, Canada (pp. 683-707), August 1991.

Naik, T. R., Singh, S., \& Hossain, M. M. (1994). Abrasion resistance of concrete as influenced by inclusion of fly ash. Cement and Concrete Research, 24(2), 303-312.

Naik, T. R., Singh, S. S., \& Hossain, M. M. (1995). Abrasion resistance of high strength concrete made with class $\mathrm{C}$ fly ash. ACI Materials Journal, 92(6), 649-650.

Naik, T. R., Singh, S. S., \& Ramme, B. W. (1997, July). Effect of source and amount of fly ash on mechanical and durability properties of concrete (pp. 157-188). ACI Special Publication, SP-170.

Naik, T. R., Singh, S. S., \& Ramme, B. W. (2002, September/ October). Effect of source of fly ash on abrasion resistance of concrete. Journal of Materials in Civil Engineering, 417-426.

Nanni, A. (1988). Curing of roller-compacted concrete and strength development. Journal of Transportation Engineering, ASCE, 114(6), 684-694.

Nanni, A. (1989). Abrasion resistance of roller-compacted concrete. ACI Materials Journal, 86(53), 559-565.

Nassif, H. H., Najm, H., \& Suksawang, N. (2005). Effect of pozzolanic materials and curing methods on the elastic 
modulus of HPC. Cement and Concrete Composites, 27, 661-670.

Nazari, A., \& Riahi, S. (2011). Abrasion resistance of concrete containing $\mathrm{SiO}_{2}$ and $\mathrm{Al}_{2} \mathrm{O}_{3}$ nanoparticles in different curing media. Energy and Buildings, 43, 2939-2946.

Neville, A. M. (1995). Properties of concrete (4th ed.). London: Longman Group UK Limited.

Park, S.-S., \& Kang, H.-Y. (2008). Characterization of fly ashpastes synthesized at different activator conditions. Korean Journal of Chemical Engineering, 25(1), 78-83.

PCA. (2005). An engineer's guide to: Building green with concrete. Skokie, IL: Portland Cement Association.

Rashad, A. M. (2013). A preliminary study on the effect of fine aggregate replacement with metakaolin on strength and abrasion resistance of concrete. Construction and Building Materials, 44, 487-495.

Rashad, A. M., Bai, Y., Basheer, P. A. M., Milestone, N. B., \& Collier, N. C. (2013). Hydration and properties of sodium sulfate activated slag. Cement and Concrete Composites, $37,20-29$

Rashad, A. M., \& Khalil, M. H. (2013). A preliminary study of alkali-activated slag blended with silica fume under the effect of thermal loads and thermal shock cycles. Construction and Building Materials, 40, 522-532.

Rashad, A. M., Seleem, H. E.-D., \& Yousri, K. M. (2009). Compressive strength of concrete mixtures with binary and ternary cement blends. Building Research Journal, 57(2), $107-130$.

Rashad, A. M., \& Zeedan, S. R. (2011). The effect of activator concentration on the residual strength of alkali-activated fly ash pastes subjected to thermal load. Construction and Building Materials, 25, 3098-3107.

Riahi, S., \& Nazari, A. (2011). Compressive strength and abrasion resistance of concrete containing $\mathrm{SiO}_{2}$ and $\mathrm{CuO}$ nanoparticles in different curing media. Science China, Technological Sciences, 54(9), 2349-2357.

Sakulich, A. R. (2011). Reinforced geopolymer composites for enhanced material greenness and durability-Review. Sustainable Cities and Society, 1, 195-210.

Siddique, R. (2001). Utilization of silica fume in concrete: Review of hardened properties. Resource, Conservation and Recycling, 55, 923-932.

Siddique, R. (2004). Performance characteristics of high-volume Class F fly ash concrete. Cement and Concrete Research, 34, 487-493.

Siddique, R. (2010). Wear resistance of high-volume fly ash concrete. Leonardo Journal of Sciences, 17(July-December), 21-36.

Siddique, R., Kapoor, K., Kadri, E.-H., \& Bennacer, R. (2012). Effect of polyester fibres on the compressive strength and abrasion resistance of HVFA concrete. Construction and Building Materials, 29, 270-278.

Siddique, R., \& Khatib, J. M. (2010). Abrasion resistance and mechanical properties of high-volume fly ash concrete. Materials and Structures, 43, 709-718.
Singh, G., \& Siddique, R. (2012). Abrasion resistance and strength properties of concrete containing waste foundry sand 9WFS. Construction and Building Materials, 28, $421-426$.

Sivasundaram, V., Carette G. G., \& Malhotra, V. M. (1990, October). Selected properties of high volume fly ash concrete. Concrete International, 47-50.

Swamy, R. N. (1986). Concrete technology and design, Volume 3 , cement replacement materials. London, U.K.: Surrey University Press, First publication.

Swamy, R. N., \& Ammar, B. (1990). Some engineering properties of slag concrete as influenced by mix proportioning and curing. ACI Materials Journal, 87(3), 210-220.

Taylor, H. F. W. (1997). Cement chemistry. London, U.K.: Thomas Telford.

Tikalsky, P. J., Carrasquillo, P. M., \& Carrasquillo, R. L. (1988). Strength and durability considerations affecting mix proportioning of concrete containing fly ash. ACI Materials Journal, 85(6), 505-511.

Toutanj, H., Delatte, N., Aggoun, S., Duval, R., \& Danson, A. (2004). Effect of supplementary cementitious materials on the compressive strength and durability of short-term cured concrete. Cement and Concrete Research, 43, 311-319.

Turk, K., \& Karatas, M. (2011). Abrasion resistance and mechanical properties of self-compacting concrete with different dosages of fly ash/silica fume. Indian Journal of Engineering and Materials Sciences, 18, 49-60.

Ukita, K., Shigematsu, S., \& Ishic, M. (1989). Improvement in the properties of concrete utilizing Classified fly ash. In Proceedings of the CANMET/ACI Third International Conference on the Use of Fly Ash, Silica Fume, Slag and Natural Pozzolans in Concrete, Trondheim, Norway (Vol. 1, pp. 219-240).

Yaxıc1, Ş., \& İnan, G. (2006). An investigation on the wear resistance of high strength concretes. Wear, 260, 615-618.

Yazici, H. (2008). The effect of silica fume and high-volume Class C fly ash on mechanical properties, chloride penetration and freeze-thaw resistance of self-compacting concrete. Construction and Building Materials, 22, 456-462.

Yen, T., Hsu, T.-H., Liu, Y.-W., \& Chen, S.-H. (2007). Influence of class $\mathrm{F}$ fly ash on the abrasion-erosion resistance of high-strength concrete. Construction and Building Materials, 21, 458-463.

Yetgin, Ş., \& Çavdar, A. (2011, February). Abrasion resistance of cement mortar with different pozzolanic compositions and matrices. Journal of Materials in Civil Engineering, ASCE, 138-145.

Ytterburg, R. F. (1971). Wear-resistant industrial floors of Portland cement concrete. Civil Engineering, ASCE, 41(1), 68-71.

Zhang, P., Li, Q., \& Zhang, H. (2011). Combined effect of polypropylene fiber and silica fume. Composites, 30(16), 1349-1358. 